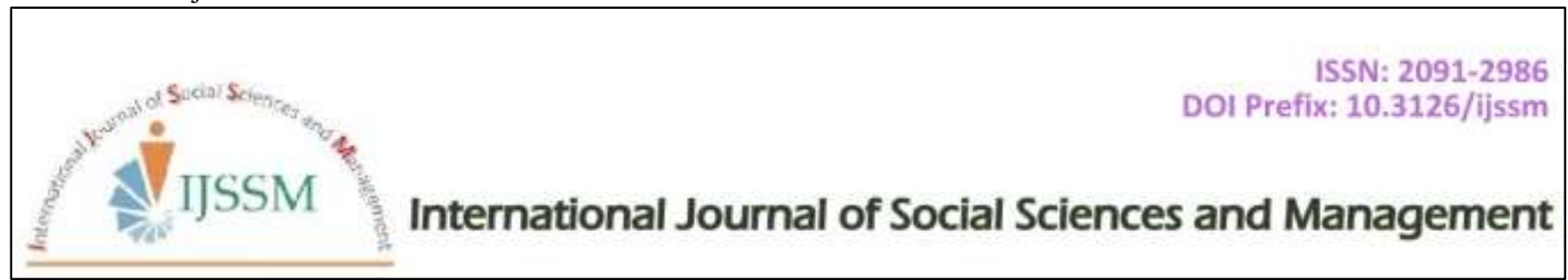

Research Article

\title{
EMOTIONAL INTELLIGENCE AND SELF-EFFICACY AS DETERMINANTS OF ETHICAL WORK BEHAVIOUR OF ARTISAN IN MAIDUGURI, BORNO STATE NIGERIA
}

\author{
Okoye Lawrence Jekwu ${ }^{1 *}$ Amos Audu ${ }^{2}$, and Oguegbe Tochukwu. M. ${ }^{3}$ \\ ${ }^{1 *}$ Department of Sociology and Anthropology, University of Maiduguri, Nigeria \\ ${ }^{2}$ Department of Education, University of Maiduguri, Nigeria. \\ ${ }^{3}$ Department of Psychology, Nnamdi Azikiwe University Awka, Nigeria \\ *Corresponding author email: laurelcrown07@gmail.com
}

\begin{abstract}
This study investigated the role of emotional intelligence and self-efficacy on ethical work behavior of artisan in Maiduguri, capital of Borno State Northeast Nigeria. The study adopted behavioural theory of obedience as its main theoretical framework. Expos facto survey design was adopted for the study. Two hundred and eight-two (282) participants were selected accidentally for the study. Results revealed that artisans who reported with high emotional intelligence were significantly different in the level of ethical work behaviour compared to those who reported low level of emotional intelligence. Emotional intelligence does not significantly predict ethical work behavior of artisan and selfefficacy significantly predict ethical work behavior of artisans. However, it shows that emotional intelligence and self-efficacy jointly predict ethical work behavior of artisan. There was no any significant main and interaction effect of emotional intelligence and self-efficacy on ethical work behaviour among artisans in Maiduguri. Female artisans significantly reported higher scores on ethical work behaviour scale than male artisans. The study however recommended that management of the organization should send their employees (artisans) on sponsored training programme of the organisation which focused on enhancing their ethical work behavior.
\end{abstract}

Keywords: Ethical work behavior; emotional intelligence; self-efficacy; artisan; Nigeria

\section{Introduction}

Ethical workplace behaviour among artisans has long been associated with management scholars and business leaders around the world. Ethical behaviour is characterized by honesty, fairness and equity in interpersonal, professional and academic relationship and it respects the dignity, diversity and the right of individual and groups of people. Moral identity had been expected to predict the performance of unethical behaviour in organizations because it acts as a self-regulatory mechanism that motivates people to make choices and pursue actions that are consistent with their moral self (Aquino \& Reed, 2002). Understanding the psychological determinants of ethical performance is important. Thus, for an organization that hire artisan to move forward in the aspect of performance, it is important for such an organization to have a good understanding of psychological factors that influences ethical workplace behavior of artisan and also take it seriously as this can undermine the competitive strength of the organization. This suggests that an individual's ethical (and unethical) behaviour in organizations is also driven by psychological construct such as emotional intelligence and self-efficacy.

Emotional intelligence is one's ability to understand and regulate one's own emotional responses as well as adapt and respond to others (Mayer, 2002). Lower emotional intelligence has been found to be associated with violent behaviour (unethical), illegal use of drugs and alcohol among workers, and participation in delinquent behaviour (Palmer and Stough, 2003). Hiring individuals with higher levels of emotional intelligence as well as training existing staff to be more emotionally intelligent has been associated with financial gains in the private sector. Many companies today are teetering on the edge of disaster. Excessive downsizing has created employees who find themselves overworked, underappreciated and constantly seesawing between exhaustion and fear. Competition in the workplace is fierce and many new recruits feel a need to turn to aggressive tactics to get ahead of their peers or risk falling behind. Business leaders are beginning to realize that such negative emotions among their employees are not healthy for the organization and its prospects for success. Although, 
artisans in most cases seem to lack self-efficacy in their profession.

Self-efficacy is the belief in one's capability to achieve a goal or an outcome. Bandura (1997) viewed self-efficacy as a person's judgement about being able to perform a particular activity. Bandura asserts that self-percepts of efficacy highly influence whether workers believe they have coping strategies to successfully deal with challenging situations i.e. ethical work behaviour in any setting. Specifically, an increase in employee "self-efficacy" has been linked to an increased tendency to engage in positive deviant behaviours.

In Nigeria today, many organizations are faced with numerous challenges such as illegal and unethical behaviour in a number of business transactions. Artisans are also faced with the challenge of evaluating the effect of this critical behaviour on the performance of such organizations. To survive, artisans resort to strategies such as doubling their productivity and making themselves indispensable; while other employees buckle under stress, get burned out and end up performing below their abilities. Ethical work behaviour of artisans had been a major problem among various work settings. This had shown a serious concern on much organisational management towards the development of their organisations when designing objectives or goals of their various settings. Thus, this study will enable the management of companies that hire artisans as employees to understand the way their employees' emotional intelligence and self-efficacy influence their expression of ethical workplace behaviours and will go a long way in guaranteeing a change for the better regarding the encouragement of such behaviours via the manipulation of the predictor variables. This study will also undoubtedly afford interested researchers the opportunity to know the impact or influence that these independent variables might have on ethical work behaviour of Artisan. It was also ascertained that there is dearth of evidence about the influence of emotional intelligence and self-efficacy on ethical work behavior of artisan. Therefore, it was to abridge this gap that this study investigated emotional intelligence and self-efficacy as determinants of ethical work behavior of artisan in Maiduguri, Nigeria.

\section{Literature Review}

\section{Theoretical Construct}

The study adopts behavioural theory of obedience as its main theoretical framework:

The behavioural theory of obedience to ethical work is based on the principle of operant conditioning proposed by B. F. Skinner (1953). The key to operant conditioning is the immediate reinforcement of any response that moves the organism (person) towards the target behaviour i.e. ethical behaviour in any settings. Reinforcement, which strengthens the behaviour, can be either positive or negative. Positive reinforcement means that a positively valued stimulus is added to the situation, thus strengthening that behaviour and increasing the probability that it will recur. An example of positive reinforcement of obedience to ethical behaviour would be a monetary payment or award contingent on any artisan keeping ethical conduct of their professions. This will be done through training by encouraging their staffs to show good emotional intelligence and high self-efficacy in any tasks given by the organization. Negative reinforcement behaviour is strengthened by the removal of an unpleasant or negatively valued stimulus. Punishment may also change behaviour but Psychologists hardly use it to lessen unethical behaviours. Punishment, including threats of employee's sack or withdraw of employee's professional certificate, is seldom useful in improving a worker's adherence on their professional ethics. Advocates of the behavioural theory use cues, rewards, and contracts to reinforce ethical workplace behaviour of Artisans.

\section{Empirical Review}

Researchers have determined that the ethical climate of an organization is a good predictor of unethical behaviour (Robinson \& Bennett, 1995). Peterson (2002) conducted a study to determine whether deviant workplace behaviour could possibly be predicted from the ethical climate of an organization. The results obtained indicated several correlations between the type of deviance and the climate identified in the organization. The clearest relationship was between Political Deviance and a Caring climate. The implication is that when employees feel that the organization is concerned with the welfare of its workers, they are less likely to experience, or engage in, political deviance. Haines \& Leonard (2007) purported that employees' attitude toward ethical behaviour at work shows significant impact on their individual characteristics. In his study, 252 Lithuanian employees (90 men and 162 women; mean age 32.10) from different organizations participated in the study. Most of them were working in the medium size private capital service organizations. Self-report questionnaire consisting of scales measuring attitude towards ethical behaviour (recognition of ethical dilemma, approval of ethical decision, and intention of ethical behaviour), three cognitive competencies (Consistency of risk perception, resistance to framing effect, and resistance to sunk cost effect), empathy and some demographic questions was used in this cross-sectional survey. The results showed neither gender nor work experience differences in attitudes towards ethical behaviour at work, but some age differences in these attitudes were found. Jordan and Troth (2004) found that it was important to distinguish between abilities related to dealing with self (own emotions) and abilities relating to how we deal with others (others' emotions) which enhanced their ethical 
behaviour. (Mitchell et al., 2008) provided preliminary empirical support for the proposition that ethical efficacy strengthens individuals 'self-regulatory mechanisms, which may mitigate the impact of supervisory unethical behavior on employees.

Based on the literature review, the following research questions are raised to guide the conduct of the study:

I. Will there be a significant difference between artisans with high and low level of emotional intelligence on ethical work behaviour?

II. To what extent will emotional intelligence and self-efficacy predict ethical work behaviour of Artisans?

III. Will there be main and interaction effect of emotional intelligence and self-efficacy on ethical work behaviour of artisans?

IV. Will there be a significant difference between male and female artisans on ethical work behaviour?

\section{Methodology}

The Expos facto survey design was adopted for the study. The two independent variables in the study are emotional intelligence and self-efficacy; and dependent variable is ethical work behavior. The study was carried out in Maiduguri, capital of Borno State, Northeastern part of Nigeria. The Participants of the study were drawn from the population of artisans selected from the department of Works and Maintenance, University of Maiduguri (i.e. Electrical, Carpentry, Power-house generating, Mechanics, and Steel Construction Workshops), Hadiza Artists Nig
Gallery; Yahaya Furniture \& CO and GC Construction Company across the city of Maiduguri in Borno State. The psychological instrument used for quantitative data collection is a standardized structured questionnaire. Data were gathered through personally administered questionnaires using accidental sampling on artisans. From this current study, the cronbach alpha coefficient of 0.88 , 0.85 and 0.79 was established. SPSS20.0 was used to analysis the result obtained from the study.

\section{Results}

From Table 1, the result shows that artisans who reported with high emotional intelligence $(\mathrm{M}=104.59$, S.D. $=6.13)$ were significantly different in the level of ethical work behaviour compared to those who reported low level of emotional intelligence $(M=103.06, \quad S . D .=5.72)$ Demonstrating that there was a significant difference in ethical work behaviour reported by artisans with high and low of emotional intelligence ( $\mathrm{t}(279)=-2.589, p<.05)$. Thus, it could be said that emotional intelligence influences the level of ethical work behaviour among the respondent sampled.

The results in table 2 showed that emotional intelligence does not significantly predict ethical work behavior of artisan, $\left(\mathrm{t}=.346, \mathrm{P}>.05, \mathrm{R}=.469, \mathrm{R}^{2}=.330, \beta=.070\right)$. However, it shows that self-efficacy significantly predict ethical work behavior of artisan, $(\mathrm{t}=3.459, \mathrm{P}<.05, \mathrm{R}=.469$, $\mathrm{R}^{2}=.330, \beta=.320$ ). Lastly, emotional intelligence and selfefficacy jointly predict ethical work behavior of artisan, $[\mathrm{F}$ $\left.(3,227)=6.587, \mathrm{P}<.05, \mathrm{R}=.469, \mathrm{R}^{2}=.330\right]$.

Table 1: $\mathbf{t}$-test summary table showing difference between artisans with low and high level of emotional intelligence on ethical work behaviour.

\begin{tabular}{|l|l|l|l|l|l|l|}
\hline Emotional intelligence & $\mathbf{N}$ & Mean & SD & df & $\mathbf{t}$ & $\mathbf{P}$ \\
\hline Low & 130 & 103.06 & 5.72 & & & \\
\hline Ethical work behaviour & & & & 279 & -2.589 & $<.05$ \\
\hline High & 151 & 104.59 & 6.13 & & & \\
\hline
\end{tabular}

Table 2: Multiple Regression summary showing joint influence of emotional intelligence and self-efficacy on ethical work behavior.

\begin{tabular}{|l|l|l|l|l|l|l|l|}
\hline Variable & $\mathbf{R}$ & $\mathbf{R}^{2}$ & $\mathbf{F}$ & $\mathbf{P}$ & $\boldsymbol{\beta}$ & $\mathbf{T}$ & $\mathbf{P}$ \\
\hline Emotional intelligence & .469 & .330 & 6.587 & $<.05$ & .070 & .346 & $>.05$ \\
\hline Self-efficacy & & & & & .320 & 3.459 & $<.05$ \\
\hline
\end{tabular}

Dependent Variable: Ethical work behavior. 
Table 3: Summary of $2 \times 2$ ANOVA showing the main and interaction effect of emotional intelligence and selfefficacy on ethical work behaviour.

\begin{tabular}{llllll}
\hline Source & Type III Sum of Squares & Df & Mean Square & F & Sig \\
\hline Emotional intelligence & 7.08 & 1 & 7.080 & .313 & $>.05$ \\
Self-efficacy & 81.57 & 1 & 81.57 & 3.61 & $>.05$ \\
Emotional intelligence*Self-efficacy* & 3.32 & 1 & 3.32 & 0.147 & $>.05$ \\
Error & 6174.226 & 273 & 22.616 & & \\
Corrected Total & 6831.744 & 280 & & & \\
\hline
\end{tabular}

Table 4: t-test summary showing difference of artisans' gender on ethical work behaviour.

\begin{tabular}{lllllll}
\hline Gender & N & Mean & SD & df & t & P \\
\hline Male & 159 & 101.55 & 4.64 & & & \\
Ethical work behaviour & & & & 280 & -4.112 & $<.01$ \\
Female & 123 & 103.45 & 4.82 & & & \\
\hline
\end{tabular}

From Table 3, the result presented shows that there was no main effect of emotional intelligence $(\mathrm{F}(1,273)=0.313$, $\mathrm{p}>.05$ ) on ethical work behaviour. There was also no significant main effect of self-efficacy on ethical work behaviour $(\mathrm{F}(1,273)=3.61, \mathrm{p}>.05)$. Finally, the result presented on the table revealed that there were no interaction effect between emotional intelligence and selfefficacy on ethical work behaviour $(\mathrm{F}=(1,273)=0.147$, $\mathrm{p}>.05$ ). It means that there was no any significant main and interaction effect of the two independent variables on the dependent variable among artisans in Maiduguri. That is, artisan shows negative interaction effect towards independent variables on dependent variable.

From Table 4, the result presented shows that female artisans $(M=103.45$, S.D. $=4.82)$ significantly reported higher scores on ethical work behaviour scale than male artisans $(M=101.55$, S.D. $=4.64)$. Female artisans reported to have more ethical work behaviour $(\mathrm{t}(280)=-4.112$, $p<.01)$ than male artisans in their workplaces. This implies that gender significantly influence ethical work behaviour among artisans sampled. That is, gender plays a significant role on artisans' ethical work behavior.

\section{Discussion}

This study investigated the role of emotional intelligence and self-efficacy on ethical work behavior of artisans in Maiduguri, capital of Borno State in Northeastern part of Nigeria.

Findings of this study confirmed that significant joint influence occurred between emotional intelligence and selfefficacy on ethical work behaviour of artisans. In the result, artisans who reported high emotional intelligence were significantly different in the level of ethical work behaviour compared to those who reported low level of emotional intelligence; demonstrating that a significant difference occurred in ethical work behavior by artisans with high and low of emotional intelligence. Thus, it could be said that emotional intelligence does influenced the level of ethical work behaviour among the respondent sampled. The findings of the current study are consistent with those of Jordan and Troth (2004) who found that it was important to distinguish between abilities related to dealing with self (own emotions) and abilities relating to how we deal with others (others' emotions) which enhanced their ethical behaviour. From the result, emotional intelligence does not significantly predict ethical work behavior of artisan. However, it shows that self-efficacy significantly predicts ethical work behavior of artisans, but emotional intelligence and self-efficacy jointly predict ethical work behavior of artisan. There was no any significant main and interaction effect of the two independent variables (emotional intelligence and self-efficacy) on the dependent variable (ethical work behavior) among artisans in Maiduguri. That is, artisan shows negative interaction effect towards independent variables on dependent variable. Meanwhile, the finding reported that female artisans have more ethical work behaviour than male artisans in their workplaces. This implied that gender significantly influence ethical work behaviour among artisans. That is, gender played a significant role on artisans' ethical work behaviour.

It is imperative to state here that even though the present study provides important clues for future researches, it is not free from limitations. The research is limited in its generalizability because the participants were selected from just few organizations/firms located in the Maiduguri, capital of Borno State in Nigeria. Compared to the number 
of artisans in Borno State Nigeria, this sample size of 282 is grossly inadequate. Therefore, future researches should try increasing the number of participants by using more organizations and more states in Nigeria. Besides these, future researches should also investigate the personality traits influencing ethical work behavior of artisans.

In conclusion, it has been established that emotional intelligence and self-efficacy jointly influence ethical work behaviour of artisans. In this case, Organizational stakeholders in any settings should ensure that while trying to improve ethical work behaviour of their employees (artisans), cognizance should be given to artisans' emotional intelligence and self-efficacy. Also, there is need for artisans' (employees) training in the area of developing ethical work behaviour. Therefore, management of the organization should send their employees (artisans) on sponsored training programme of the organization which focused on enhancing their ethical work behavior.

\section{References}

Aquino K and Reed A (2002) The self-importance of moral identity. Journal of Personality and Social Psychology 83:1423-1440.

Bandura A (1997) Social foundations of thought and action: A social cognitive theory. Englewood Cliffs, N. J: PrenticeHall.
Goleman D (2001) An EI based theory of performance. In: Cherniss C \& Goleman D (Eds.) The emotionally intelligent workplace, San Francisco, Jossey-Bass. pp. 2744.

Haines R and Leonard LNK (2007) Individual Characteristics and Ethical Decision-Making in an IT Context. Industrial Managements and Data I 107: 5-20.

Jordan PJ and Troth AC (2004) Managing emotions during team problem solving: Emotional intelligence and conflict resolution, Human Performance 17: 195-218.

Mayer JP (2002) Human abilities emotional intelligence. Annual review of psychology 59: 507-536.

Mitchell MS, Palmer NF and Schminke M (2008) Understanding the influence of ethical efficacy. Paper presented at the annual meeting of the Academy of Management, Anaheim, $C A$.

Palmer B and Stough C (2001) Swinburn University Emotional Intelligence Test: Interim technical manual - Version 2. Melbourne: Swinburne University.

Peterson DK (2002) Deviant workplace behavior and the organization's ethical climate. Journal of Business and Psychology 17: 47-61.

Robinson SL and Bennett RJ (1995) A typology of deviant workplace behaviours: A multi-dimensional Scaling study. Academy of Management Journal 38: 555-572.

Skinner BF (1953). Science and human behavior. New York: Macmillian. 